\title{
Stability-indicating Micellar enhanced Spectro-fluorometric Determination of Daclatasvir in its tablet and Spiked Human Plasma
}

\author{
Maha A. Sultan ${ }^{\mathrm{a}}$, Maha M. Abou El-Alamin ${ }^{\mathrm{a}}$, Alastair W. Wark ${ }^{\mathrm{b}}$ and Marwa M. Azab*a \\ ${ }^{a}$ Analytical Chemistry Department, Faculty of Pharmacy, Helwan University, 11795, Cairo, Egypt \\ ${ }^{b}$ Centre for Molecular Nanometrology, WESTChem, Dept. of Pure \& Applied Chemistry, Technology \\ \& Innovation Centre, University of Strathclyde, Glasgow, G1 1RD, UK..
}

*Corresponding author: Email: dr.marwitasino@gmail.com Tel: +2 (0)1000191556.

\begin{abstract}
A fast, simple and sensitive micellar enhanced spectrofluorimetric method is performed for the determination of Daclatasvir dihydrochloride (DAC) in its pharmaceutical dosage form and in spiked human plasma. The fluorescence intensity (FI) was measured at $367 \mathrm{~nm}$ after excitation at $300 \mathrm{~nm}$. In aqueous solution, the FI of DAC was greatly enhanced by more than $110 \%$ in the presence of sodium dodecyl sulphate (SDS). The detection method was linear over the range of 12.93 to $161.60 \mathrm{ng} / \mathrm{mL}$, with a limit of detection of $1.75 \mathrm{ng} / \mathrm{mL}$. The proposed method was successfully applied to the determination of DAC in its pharmaceutical dosage form and the mean $\%$ recovery of DAC in spiked human plasma was $95.42 \pm 2.52$. The developed methodology was also extended to stress studies of DAC after exposure to different forced degradation conditions including acidic, alkaline, photolytic, thermal and oxidative environments.
\end{abstract}

Keywords: Daclatasvir dihydrochloride (DAC) detection, Spectrofluorimetry; spiked human plasma. 


\section{Introduction}

Hepatitis $\mathrm{C}$ virus (HCV) infection rates are approximately 130 million people with the majority suffering from chronic infections as chronic liver disease, cirrhosis and hepatocellular carcinoma. Mortality because of HCV infection is a main cause of death among HIV-positive patients and one of the highest HCV infection rates (15-20\%) has been reported from Egypt [1-3].

(HCV) treatment has achieved significant advances with the help of new directacting antivirals. Nucleotide polymerase inhibitors are a class of the new treatment that have been proven to be highly effective and safe as part of an antiviral regimen [4]. Daclatasvir (DAC) (Fig. 1) Methyl[(2S)-1-[5]-2pyrrolidinyl]-1H-imidazol-4-yl\}-4-biphenylyl)-1H-imidazol-2-yl]-1-

pyrrolidinyl \}-3-methyl-1-oxo-2-butanyl]carbamate is a highly effective and selective direct acting antiviral of $\mathrm{HCV}$ [6], and is specifically active against NS5A, a non-structural protein encoded by HCV. DAC binds to the $\mathrm{N}$-terminus of NS5A within domain 1 of the protein, inhibiting both viral RNA replication and virion assembly resulting in structural distortions that interfere with NS5A functions. DAC was approved for use in combination with other antiviral agents as a therapy for chronic hepatitis C in the United States in 2015 [7]. Current indications are limited to patients with HCV genotype 3, although several studies have shown that DAC is also active against other HCV genotypes [8]. 


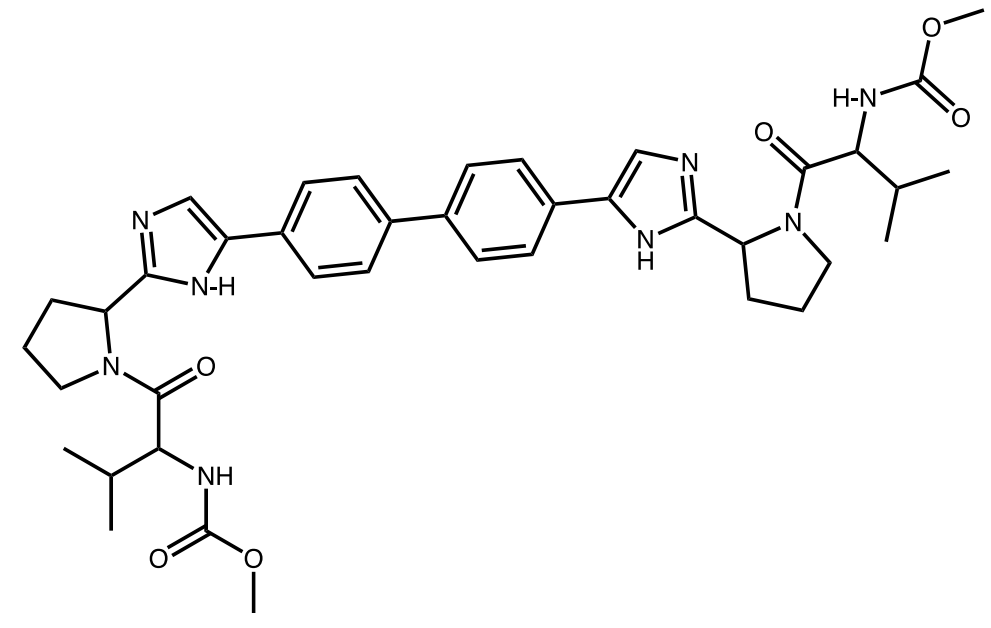

\section{Figure 1. Chemical structure of Daclatasvir Dihydrochloride $\left(\mathrm{C}_{40} \mathrm{H}_{52} \mathrm{Cl}_{2} \mathrm{~N}_{8} \mathrm{O}_{6}\right)$.}

In this article, we introduce a new fluorescent-based assay capable of sensitively and specifically detecting DAC in pharmaceutical dosage form and in spiked human plasma. This compares to the relatively few literature reports which describe the use of high performance liquid chromatography [9-11], liquid chromatography-mass spectrometry (LC-MS) [5, 12], electrochemistry [13] and spectrophotometry $[14,15]$ for DAC determination. To the best of our knowledge, a spectrofluorimetric method for DAC determination has been reported only once recently [16] and did not analyse DAC in the presence of its degradation products. This motivated us to develop and validate a stability indicating spectrofluorimetric assay for the quality control of DAC in pharmaceutical dosage form and spiked human plasma by introducing a micellar enhancement of the native fluorescence intensity (FI) of DAC. A simple and highly sensitive spectrofluorimetric method has been developed for the determination of DAC in pure form, tablets and in spiked plasma. Micellar media allows increasing the FI of target fluorophores by lowering the limit of detection and thus increasing their sensitivity [17]. Sodium dodecyl sulphate (SDS), has 
been used for the determination of many pharmaceutical compounds [18-20]. The critical micelle concentration (CMC) of SDS in pure water at $25^{\circ} \mathrm{C}$ is $8.2 \times 10^{-3}$ $\mathrm{M}$ and the aggregation number at this concentration is usually considered to be 62 [21]. The method developed here is simple, time-saving and does not require a tedious multi-step procedure. Another significant advantage is avoiding the use of volatile and corrosive organic solvents for target extraction. The performance of the micellar enhanced spectrofluorimetric method was validated with the aim of demonstrating the potential for direct analysis of human samples at clinically relevant concentrations.

\section{Experimental:}

\subsection{Instruments}

The fluorescence spectra and measurements were obtained using a JASCO FP 6200- Spectrofluorimeter equipped with a $150 \mathrm{~W}$ xenon lamp, a recorder and using a $1.0 \mathrm{~cm}$ quartz cell. Instrument excitation and emission slits were both adjusted to $5 \mathrm{~nm}$. Spectra were evaluated using Spectra Manager FP-6200 Control Driver software, Version 1.54.03 [Build 1], JASCO Corporation.

\subsection{Materials and reagents}

\subsubsection{Pure materials}

DAC purity (99.2\%) batch number (PO-20131121-01) was kindly supplied from NODCAR (Cairo, Egypt).

\subsubsection{Pharmaceutical dosage form}


Daklanork® tab (MSD, Egypt), Batch no. M1010417, 65.92 mg Daclatasvir dihydrochloride equivalent to $60 \mathrm{mg} \mathrm{DAC} / \mathrm{tab}$, was purchased from the local market.

\subsubsection{Chemicals and Reagents}

Sodium dodecyl sulfate (SDS) (Riedel-de Haen, Germany), $1.0 \%$ (W/V) aqueous solution was prepared by dissolving $1.0 \mathrm{~g}$ SDS in distilled water, and then diluting to $100 \mathrm{~mL}$ with the same solvent. The solution was kept stable for at least 7 days when left in a refrigerator. $\beta$-cyclodextrin $(\beta-C D)$ was obtained from Merck (Germany), $0.5 \%(\mathrm{~W} / \mathrm{V})$ aqueous solution was prepared by dissolving $0.5 \mathrm{~g} \beta-\mathrm{CD}$ in distilled water, and then it was diluted to100 $\mathrm{mL}$ with the same solvent. Phosphate buffer [potassium phosphate monobasic] was obtained from (Sigma, Germany), and prepared at $10 \mathrm{mM}$ aqueous solution $\mathrm{pH}$ $7.0 \pm 0.2$. Methanol (HPLC grade 99.9\%), 2-propanol (HPLC grade 99.9\%), ethanol (HPLC grade 99.8\%), acetonitrile (HPLC grade 99.9\%), hydrochloric acid (HPLC grade 37\%) 1.0 M aqueous solution prepared were all purchased from Sigma-Aldrich, Germany. Sodium chloride and sodium hydroxide pellets (1.0 $\mathrm{M}$ aqueous solution prepared) were obtained from Winlab, Leicestershire, U.K. Fresh human plasma samples were obtained from NODCAR (Cairo, Egypt) and were kept frozen until use after gentle thawing. Double distilled water was used throughout all experiments.

\subsection{DAC Solutions}

\subsubsection{Standard stock solution}

Stock 1: A stock standard solution of DAC reference standard $(400 \mu \mathrm{g} / \mathrm{mL})$ was prepared by dissolving $10 \mathrm{mg}$ standard DAC in double distilled water and the volume was completed to $25 \mathrm{~mL}$ using the same solvent. 
Stock 2: $1 \mathrm{~mL}$ of stock 1 was transferred into a $25 \mathrm{~mL}$ volumetric flask (16 $\mu \mathrm{g} / \mathrm{mL}$ ) and then completed to the mark with the same solvent.

\subsubsection{Standard working solution}

A DAC working standard solution $(640 \mathrm{ng} / \mathrm{mL})$ was prepared by transferring 1 $\mathrm{mL}$ of stock 2 solution into a $25 \mathrm{~mL}$ volumetric flask and completing to the mark with water.

\subsection{Procedures}

\subsubsection{Construction of the Calibration Curves.}

Aliquots from DAC working solution equivalent to 12.93-161.60 ng DAC were carefully transferred into a series of $10-\mathrm{mL}$ volumetric flasks. Then $2.0 \mathrm{~mL} 1 \%$ SDS solution were added to each flask. The volume was completed with distilled water; the contents of the flasks were mixed well. A blank experiment was performed simultaneously, and the fluorescence spectra were recorded intensity after excitation at $300 \mathrm{~nm}$. The fluorescence intensities were measured at $368 \mathrm{~nm}$ and plotted against the final drug concentrations $(\mathrm{ng} / \mathrm{mL})$ to obtain the calibration graph. Alternatively, the corresponding regression equation was derived.

\subsubsection{Procedure for Tablet analysis}

Ten tablets were weighed and grinded to a fine powder. An amount of the ground tablet weight equivalent to $10 \mathrm{mg}$ Daclatasvir $\mathrm{HCl}$ was accurately weighed, transferred to a $25-\mathrm{mL}$ volumetric flask and dissolved in double distilled water. After sonication for $30 \mathrm{~min}$ the volume was diluted with double distilled water. The produced solution $(400 \mu \mathrm{g} / \mathrm{mL})$ was filtered with a $0.45 \mu \mathrm{m}$ disposable syringe filter and then diluted to obtain an aqueous stock solution $(16 \mu \mathrm{g} / \mathrm{mL})$. 
Aliquots from working solution covering the concentration range were transferred into a series of $10-\mathrm{mL}$ volumetric flasks, the 'Procedure for calibration graph' was then performed. The tablet content was determined from the previously plotted calibration graph.

\subsubsection{Procedures for spiked human plasma}

One $\mathrm{mL}$ of thawed human plasma were transferred into a centrifuge tube, diluted with $1 \mathrm{~mL}$ of $0.1,0.31$ and $0.52 \mu \mathrm{g}$ DAC and deproteinized with $2 \mathrm{~mL} \mathrm{ACN}$, then vortex mixing. Final concentrations were 25.00, 77.60 and $129.28 \mathrm{ng} / \mathrm{mL}$ DAC. The solutions were centrifuged at $5000 \mathrm{rpm}$ for 15 minutes. The solutions were then filtered through a disposable syringe filter $(0.45 \mu \mathrm{m})$ and the same procedure as described for the production of the calibration graph was followed. The experiment was carried out and each solution was prepared in triplicate. The concentration of DAC in plasma was then calculated based on the calibration plot.

\subsubsection{Procedures for stability indicating assay}

Intended degradation was performed using acid hydrolysis, base hydrolysis, oxidative degradation, thermal degradation and sunlight degradation. A degradation sample was prepared by transferring an accurately weighed amount of the tablets corresponding to $10 \mathrm{mg}$ of DAC declared active principle into 100 $\mathrm{mL}$ volumetric flasks, diluted with distilled water and sonicated for 30 mins. Then $4 \mathrm{~mL}$ of this solution was taken in each of five $100 \mathrm{~mL}$ round bottomed flasks to perform the degradation tests. $0.1 \mathrm{~N}$ of each $\mathrm{HCL}$ and $\mathrm{NaOH}$ were enough to assess the degradation behaviour. To the first flask, $10 \mathrm{~mL}$ of $0.1 \mathrm{~N} \mathrm{HCl}$ was added for acidic degradation. To the second flask, $10 \mathrm{~mL}$ of $0.1 \mathrm{~N} \mathrm{NaOH}$ was added for basic degradation. To the third flask, $10 \mathrm{~mL}$ of $30 \%$ (v/v) $\mathrm{H}_{2} \mathrm{O}_{2}$ was added for oxidative degradation. the fourth flask was diluted with the distilled 
water and heated at $70^{\circ} \mathrm{C}$ in a water bath. The fifth flask was diluted with distilled water and left in sunlight. After the required time, samples were treated as follows: the $\mathrm{pH}$ values of the first and second flasks were neutralized with $1 \mathrm{~N}$ $\mathrm{NaOH}$ and $1 \mathrm{~N} \mathrm{HCl}$, respectively and then the first three flasks were diluted with double distilled water to the mark. The solutions were filtered through a disposable syringe filter $(0.45 \mu \mathrm{m})$ and then serially diluted to the required volume with double distilled water. Two $\mathrm{mL}$ of the resulting solutions was then transferred into $10 \mathrm{~mL}$ volumetric flasks to obtain a concentration of $160 \mathrm{ng} / \mathrm{mL}$ DAC and the procedure described above (section 2.4.1) was performed. The nominal content of the aliquots was calculated from the calibration graph.

\section{Results and Discussion}

A stability-indicating micellar enhanced spectrofluorimetric method was developed and fully validated for the determination of DAC with several experimental parameters accurately tested and optimized. The absorption and fluorescence emission spectra of DAC are shown in Figure 2 with the native fluorescence of DAC measured at an excitation wavelength $\left(\lambda_{\text {ex }}\right)$ of $300 \mathrm{~nm}$. The fluorescence of DAC is characterized by two emission peaks at $351 \mathrm{~nm}$ and 368 $\mathrm{nm}$, exhibiting a fluorescence intensity depending on the microenvironment as seen in Figure 3. It is worth mentioning that the distinct shoulder at $351 \mathrm{~nm}$ in Figure 3 appears only when DAC is in micellar media. The literature revealed that this shoulder peak is attributed to the intercalation of polyaromatic

compounds within SDS containing media (SDS concentration $\geq 4 \mathrm{mM}$ ) as a consequence of very weak Л-Л interaction due to the incorporation of DAC into the micelle [22]. 


\subsection{Optimization of the experimental conditions}

Various experimental parameters affecting the native FI of the drug and its stability were systematically studied. Such factors include the effect of different diluting solvents as well as different buffers and surfactants.

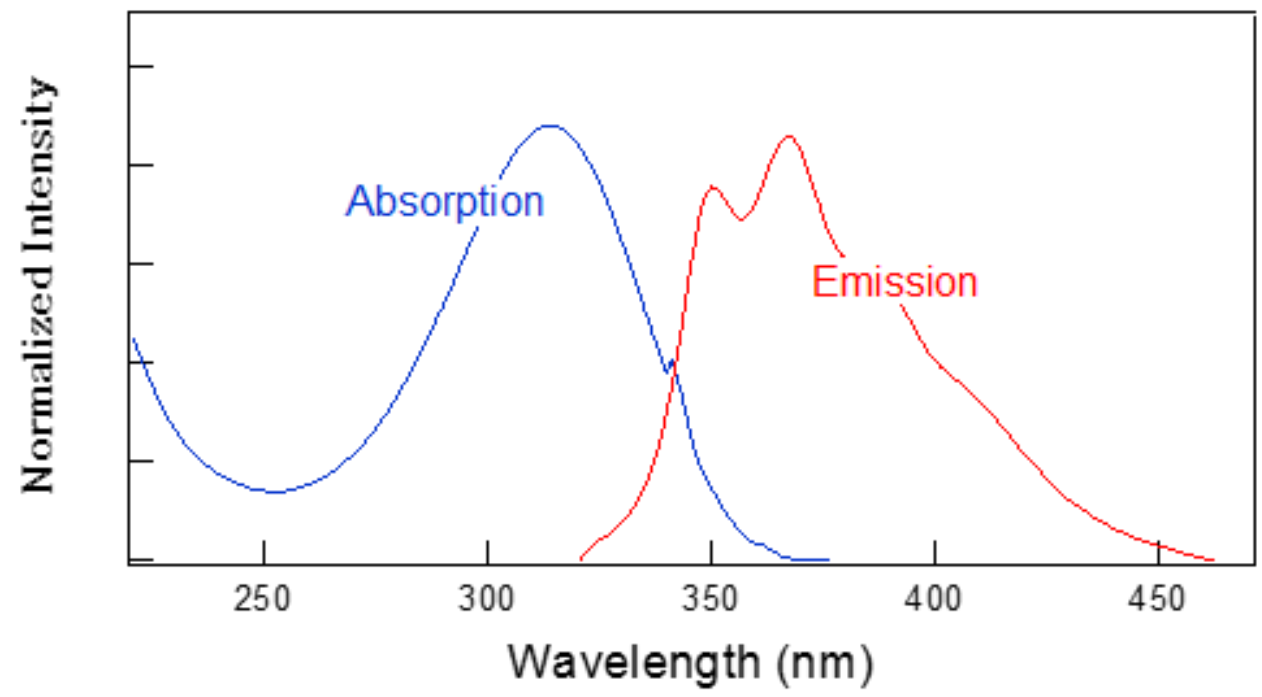

Figure 2. Absorption and emission spectra for $90 \mathrm{ng} / \mathrm{mL}$ aqueous DAC in SDS micellar media.

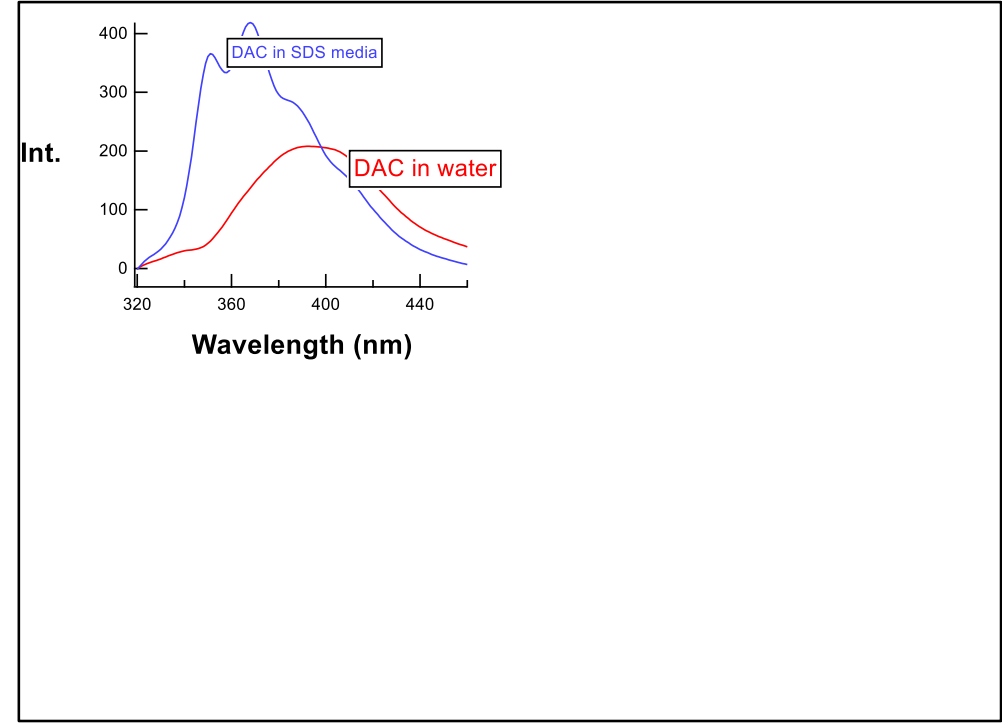


Figure 3. Fluorescence emission spectra of $90 \mathrm{ng} / \mathrm{mL}$ DAC in water and in aqueous SDS after excitation at $300 \mathrm{~nm}$.

\subsubsection{Effect of excitation wavelength}

The fluorescence intensity of DAC in water after excitation at $300 \mathrm{~nm}$ is higher than when being excited at $317 \mathrm{~nm}\left(\mathrm{DAC} \chi_{\max }\right)$, as shown in Figure 4. Therefore, $300 \mathrm{~nm}$ was chosen to be the excitation wavelength.

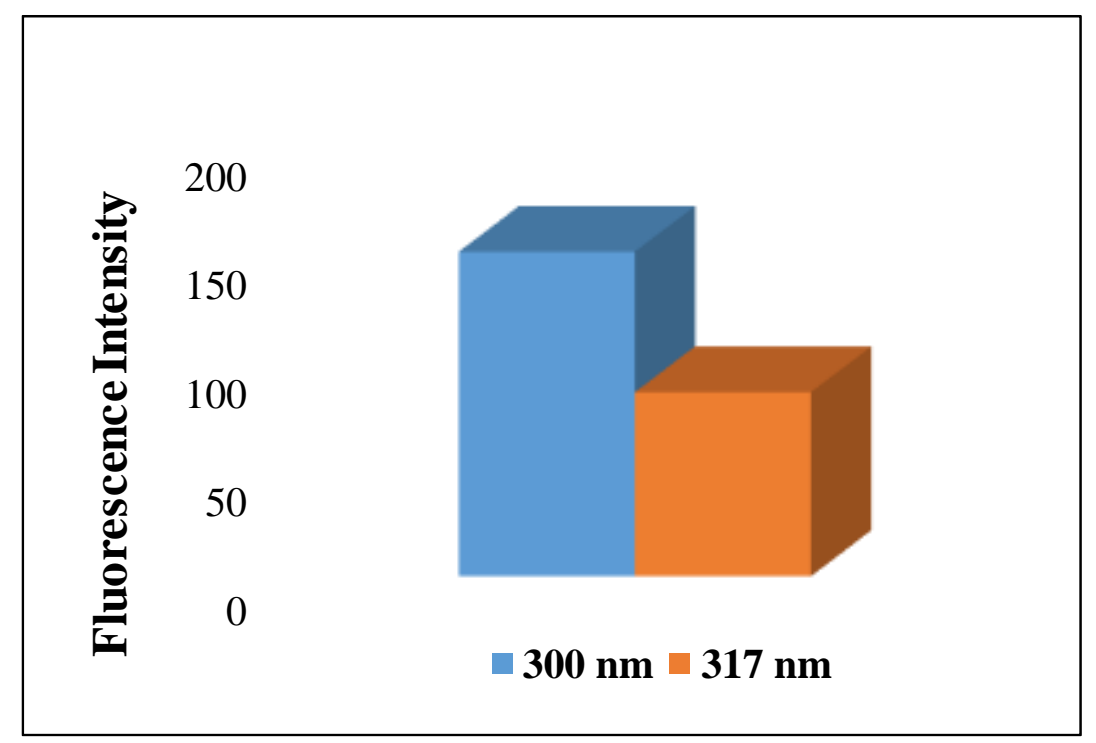

Figure 4. Effect of excitation wavelength on the fluorescence intensity of 40 $\mathrm{ng} / \mathrm{ml} \mathrm{DAC}$.

\subsubsection{Effect of diluting solvent}

The effect of different diluting solvents (methanol, ethanol, water, 2propanol and acetonitrile) on the FI of DAC was studied. As shown in Figure 5, the FI of the studied drug in methanol is slightly higher in comparison with water, but water was selected as the optimum diluting 
solvent because it is an environmentally friendly solvent, inexpensive, readily available. This circumvents the environmental problems associated with organic solvents resulting in both economic and greener chemistry advantages in support of the developed method.

Thus, using toxic, flammable, or environmentally damaging solvents would appear needless because this has no special impact on the DAC fluorescence signal intensity compared to water which has nearly the same FI at $300 \mathrm{~nm}$ excitation as the organic solvents compared. Chemists are advised to examine whether they can achieve similar special chemical results while at the same time minimizing the environmental impact associated with many solvents[23, 24]. As a result, water was subsequently used in this project.

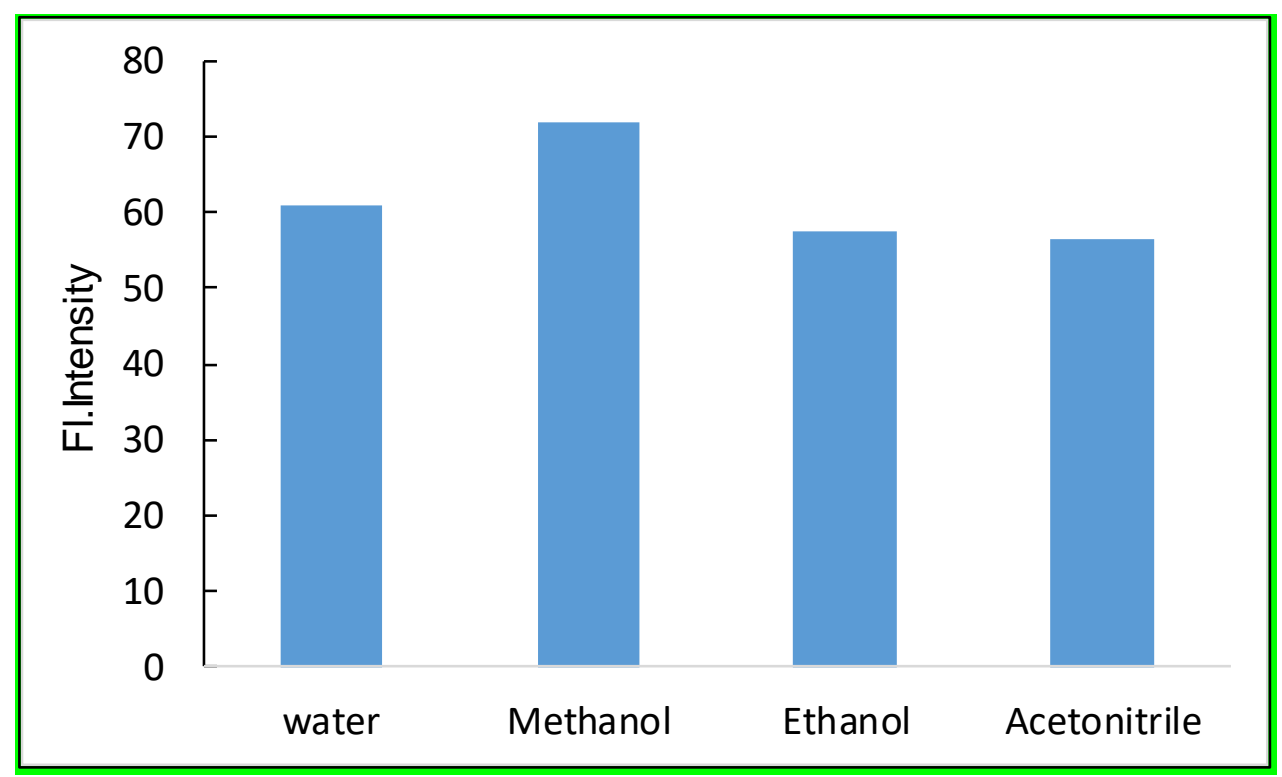


Figure 5. Effect of solvents on the FI of a $30 \mathrm{ng} / \mathrm{mL}$ DAC solution.

\subsubsection{Effect of surfactants}

The effect of different types of surfactants (SDS, $\beta-C D$ and Tween 80 ) on the fluorescence intensity of DAC was investigated. Tween 80 caused a significant decrease in the FI while the addition of SDS caused an enhancement (about $110 \%$ ) of the FI compared with aqueous solution only. This may be as a result of light scattering by SDS micelles. On the other hand, $\beta$-cyclodextrin showed no marked effect on the FI of DAC, as shown in Figure 6. Therefore, SDS was used as a fluorescence enhancer to develop a new micellar enhanced spectrofluorimetric method for the determination of DAC in its pure form, dosage form and in spiked human plasma.

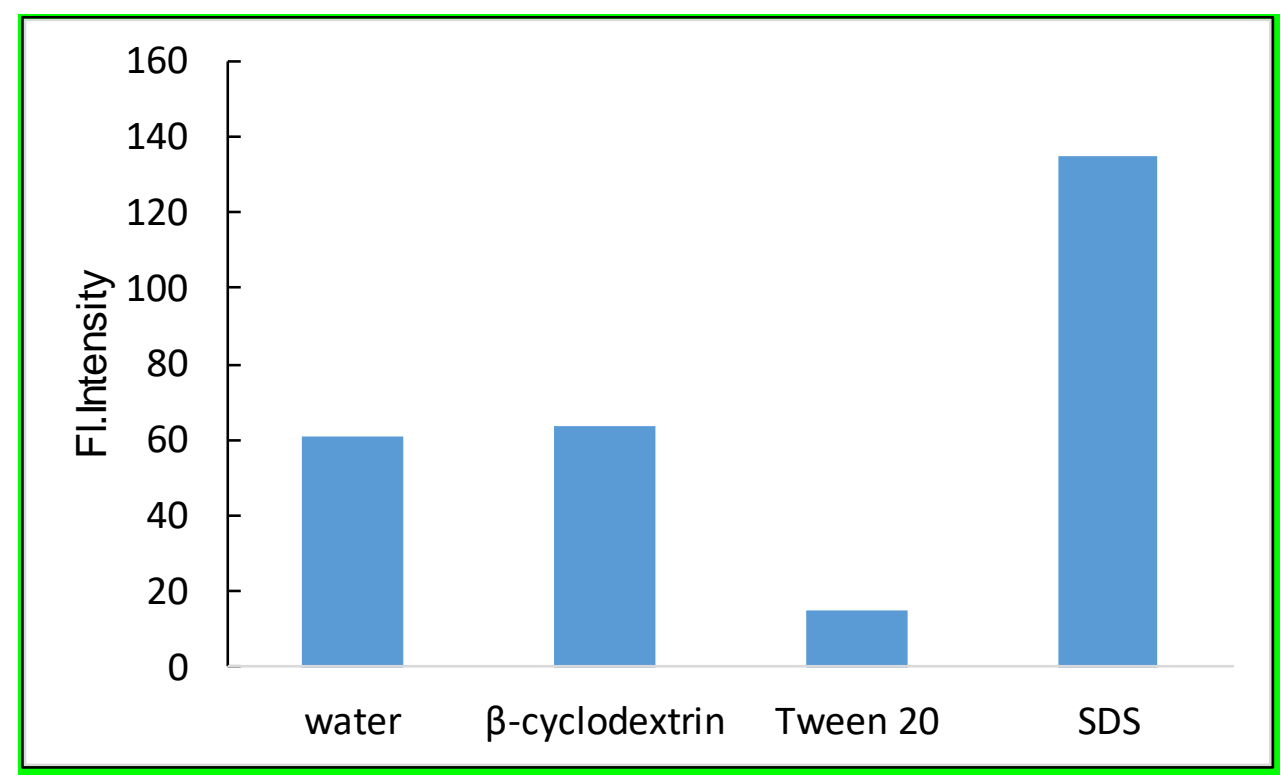

Figure 6. Comparing the effect of $1 \%(w / v)$ SDS, $0.5 \%(w / v)(\beta-C D)$ and Tween 20 on the FI of an aqueous solution of $30 \mathrm{ng} / \mathrm{mL}$ DAC. 


\subsubsection{Effect of $p H$}

The influence of $\mathrm{pH}$ on the fluorescence intensity of DAC was studied using 10 $\mathrm{mM}$ phosphate buffer covering a $\mathrm{pH}$ range of 2 to 9 . It was found that the highest FI was obtained at pH 7 and lower FI's observed at both more acidic and basic $\mathrm{pH}$ values (see Figure 7). Importantly, there was little variation in FI between $\mathrm{pH}$ 7 buffer and water only. This establishes the optimum conditions as being in water without $\mathrm{pH}$ adjustment.
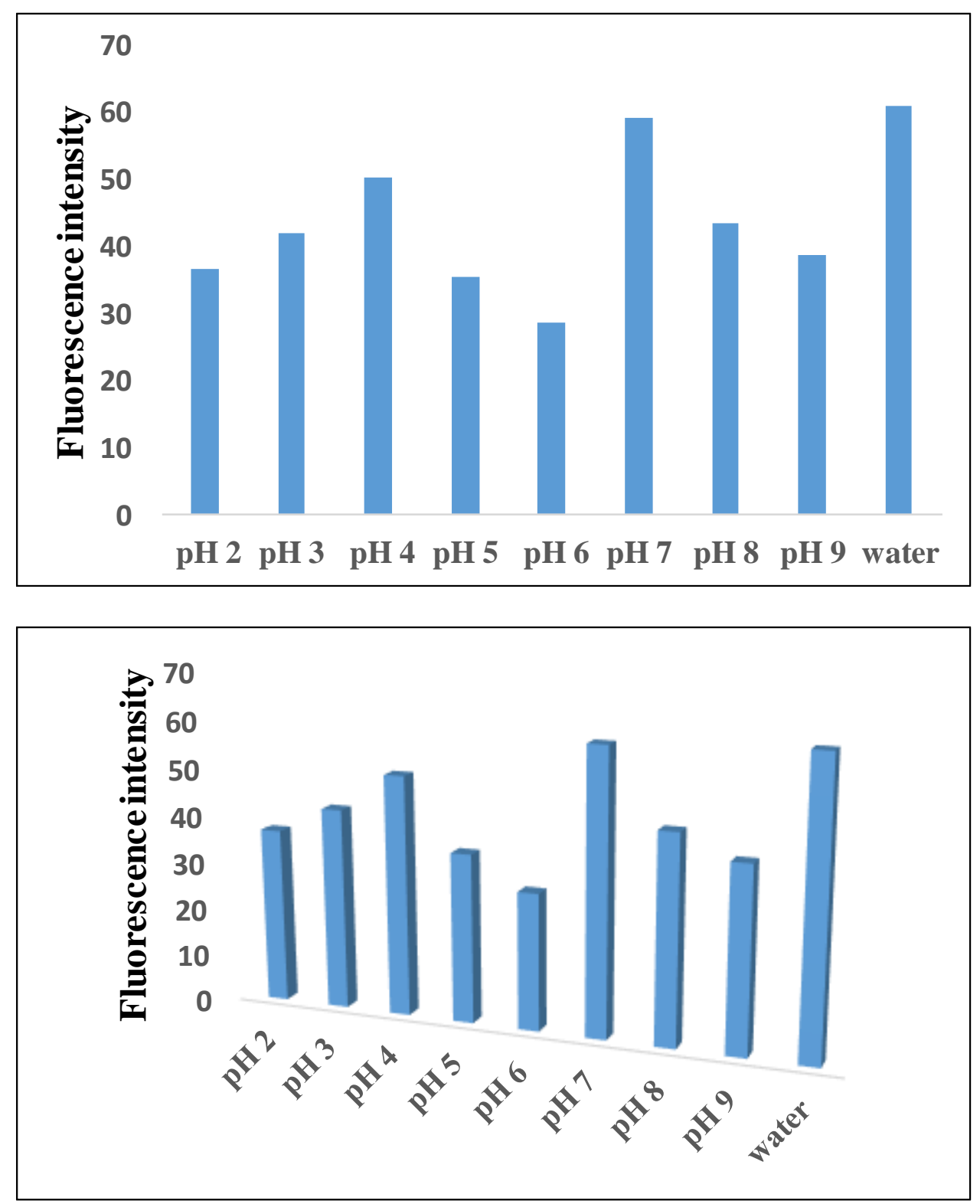

Figure 7. Effect of $\mathrm{pH}$ on the FI of a $30 \mathrm{ng} / \mathrm{mL}$ aqueous solution of DAC. 


\subsubsection{Effect of SDS concentration}

The influence of SDS concentration on the FI of DAC was studied using increasing volumes of $1.0 \% \mathrm{w} / \mathrm{v}$ SDS. It was found that increasing SDS concentration (0.69-17.25 $\mathrm{mM})$ resulted in a consequent increase in FI up to $6.9 \mathrm{mM}$. Beyond this concentration, a decrease in the FI was observed (Figure 8). Therefore, $6.90 \mathrm{mM}$ SDS solution was chosen as the optimum SDS concentration to achieve maximum enhancement in the FI of DAC. This is related to the observation that the DAC FI increases with increasing SDS concentration and reaches a maximum close to the critical micelle concentration of SDS $(6 \mathrm{mM})[25,26]$, which is advantageous for increasing the effective absorption cross section of the complex causing increase of molar absorbancy index [27].

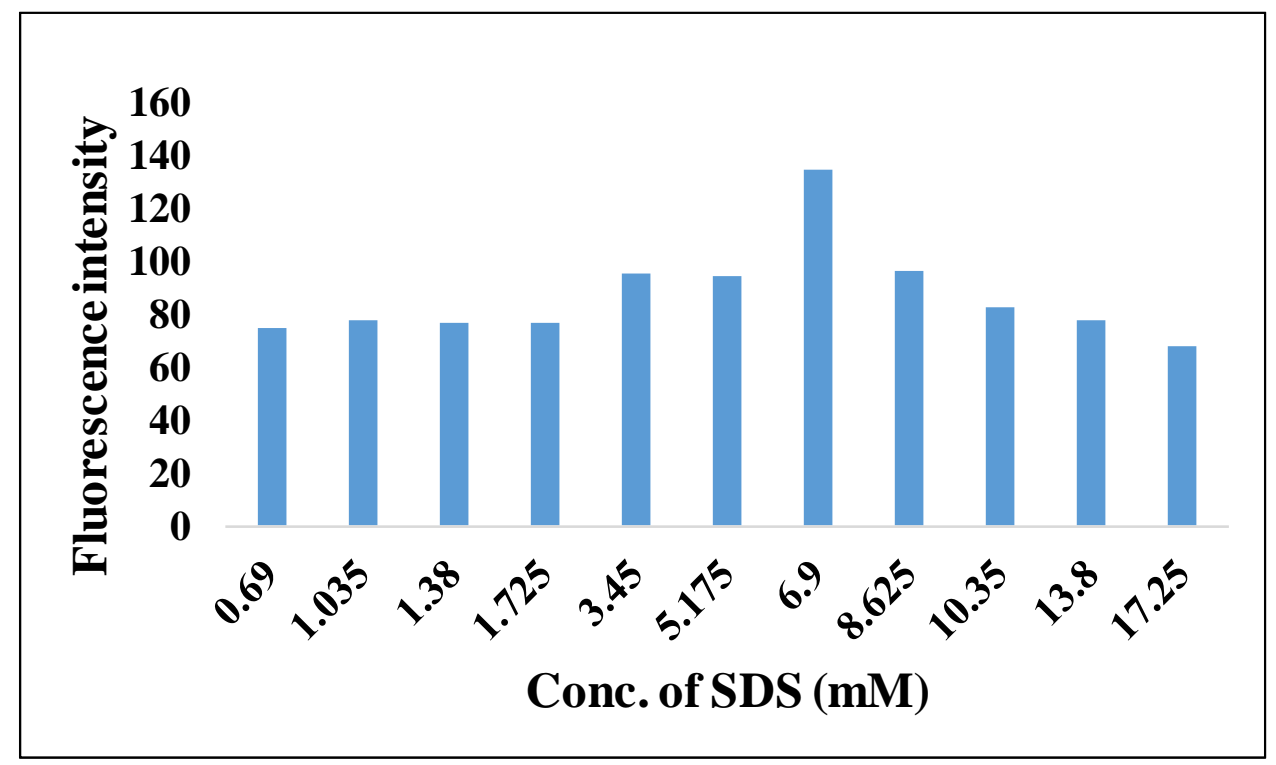

Figure 8. Effect of SDS concentration on the fluorescence intensity of $30 \mathrm{ng} / \mathrm{mL}$ DAC. 


\subsubsection{Effect of time}

The effect of mixing time between DAC and SDS on the FI of DAC was studied over time intervals ranging from five minutes up to 30 minutes. It was found that the enhancement of the FI was immediately developed and remained stable for 30 minutes as shown in Figure 9. Also, the effect of time on the FI of DAC was studied and it was found that the enhancement of the FI was immediately developed and remained stable for more than $2 \mathrm{hrs}$.

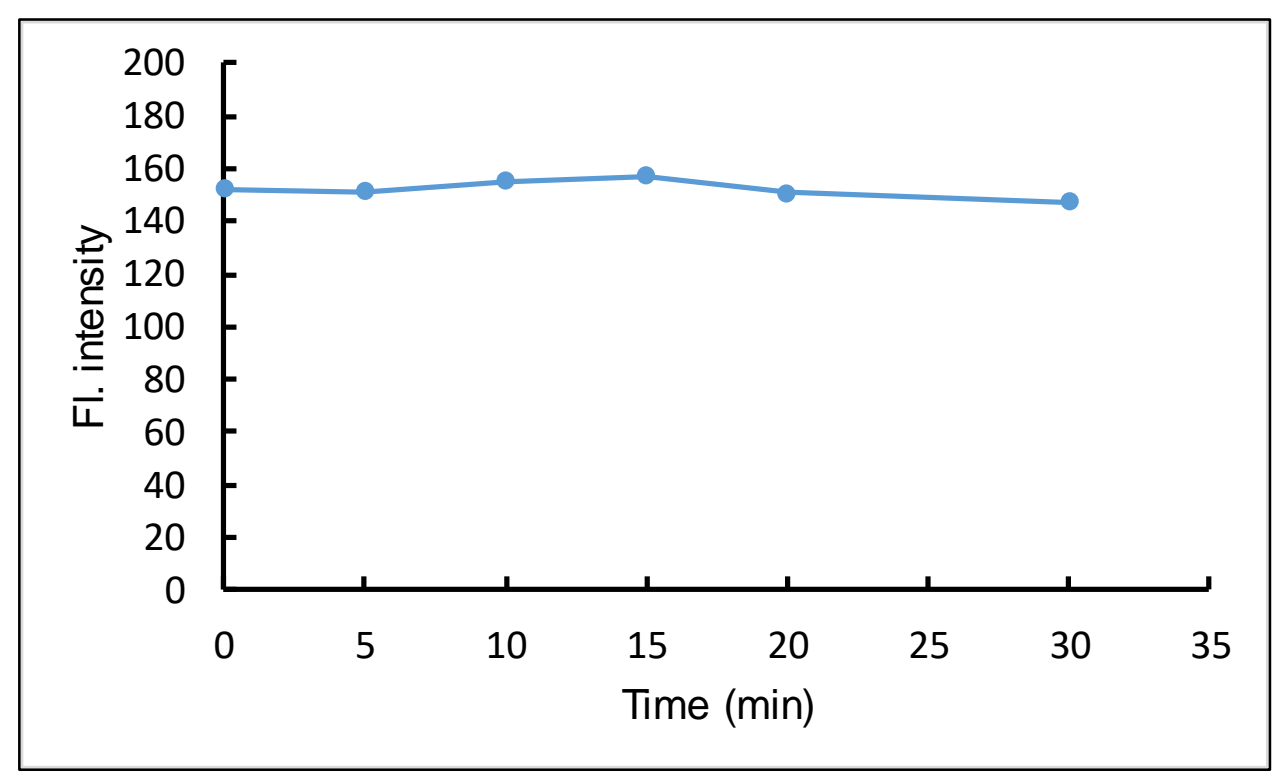

Figure 9. Effect of time on the fluorescence intensity of $30 \mathrm{ng} / \mathrm{mL}$ DAC in $1 \%$ SDS micellar media.

\subsection{Validation of the micellar enhanced spectrofluorimetric method}

The validity of the proposed method was assessed by studying the following parameters: linearity, range, LOD, LOQ, precision, accuracy, robustness and specificity, according to ICH guidelines [28]. 


\subsubsection{Linearity and Range}

A linear relationship between DAC concentration and native fluorescence was obtained over the concentration range of $12.93-161.60 \mathrm{ng} / \mathrm{mL}$ as shown in Figure 10. The results showed good linearity with regression parameters calculated according to ICH guidelines as in Table 1. The regression equations were computed and found to be: $F I=3.777 \mathrm{C}+73.877,\left(\mathrm{R}^{2}=0.9993\right)$ where $\mathrm{C}$ is the DAC concentration in $\mathrm{ng} / \mathrm{mL}$. The linearity of the calibration graph is indicated by the high correlation coefficient $(\mathrm{R})$ value and the small value of residual standard deviation $\left(\mathrm{S}_{\mathrm{y} / \mathrm{x}}\right)$ which measures the extent of deviation of the actual data points from the regression line.

The limit of quantitation (LOQ) was determined by establishing the lowest concentration that can be measured according to $\mathrm{ICH}$ recommendations. The limit of detection (LOD) was determined by evaluating the lowest concentration of the analyte that can be readily detected. The values of LOQ and LOD were calculated according to the following equations:

$$
\mathrm{LOQ}=10 \sigma / \mathrm{S} \text { and } \mathrm{LOD}=3.3 \sigma / \mathrm{S}
$$

where $\sigma=$ the residual standard deviation of the response and $S=$ slope of the calibration curve. The measured LOQ and LOD values are included in Table 1. The proposed method was evaluated by calculating accuracy as percent relative error and precision as percent relative standard deviation, the results are shown in Table 1. 
Table 1. Regression parameters obtained from the calibration curve of DAC in $1 \%$ SDS micellar media. RSD is the relative standard deviation and SE is the standard error.

\begin{tabular}{|l|l|}
\hline Parameter & Results \\
\hline Concentration range (ng/ml) & $12.93-161.60$ \\
\hline Limit of detection & 1.749 \\
\hline Limit of quantification & 5.30 \\
\hline Correlation coefficient & 0.9993 \\
\hline Slope & 3.777 \\
\hline Intercept & 73.877 \\
\hline Standard deviation of residuals & 2.00 \\
\hline S.D. of intercept $\left(\mathrm{S}_{\mathrm{a}}\right)$ & 4.89 \\
\hline S.D. of slope $\left(\mathrm{S}_{\mathrm{b}}\right)$ & 0.05 \\
\hline \%RSD(SD X 100/X')SD=2.37, x' 99.4 & 2.38 \\
\hline \%error & 0.97 \\
\hline
\end{tabular}


(A)

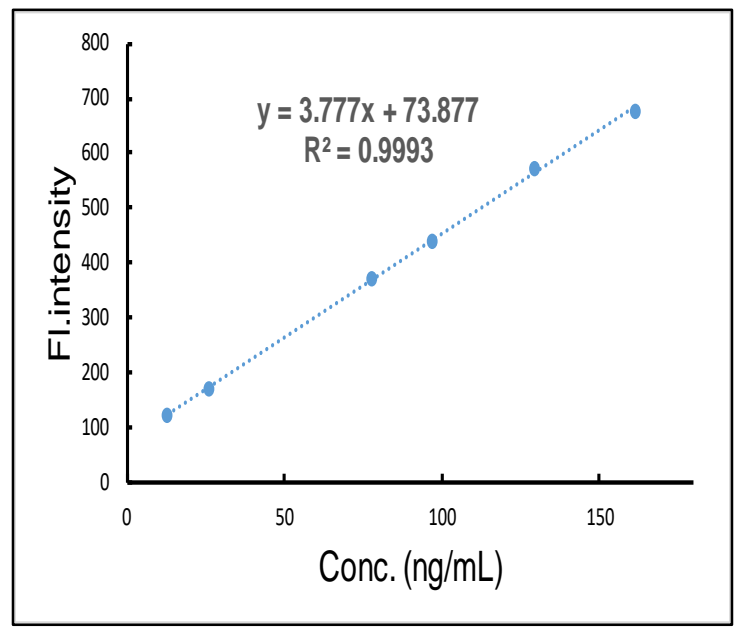

(B)

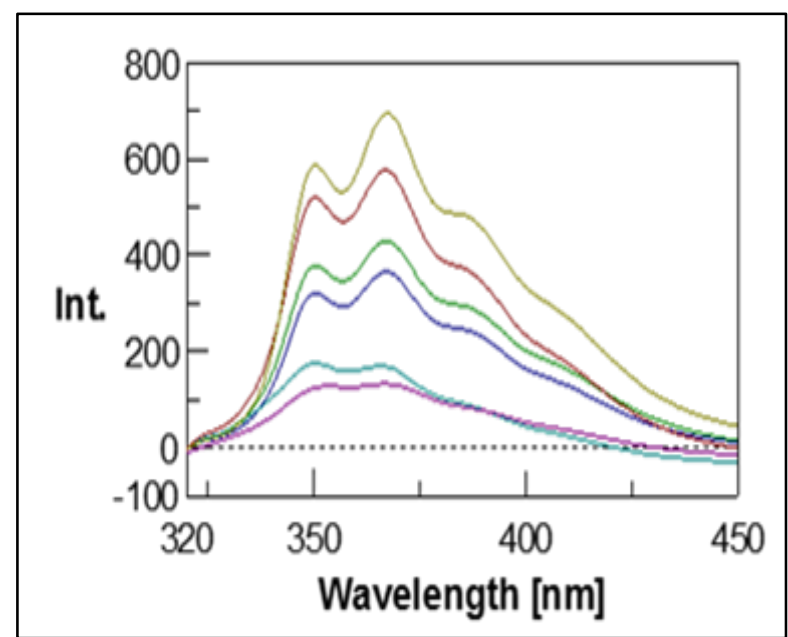

Figure 10. (A) Calibration curve of (12.93-161.60 ng/mL) DAC using $1 \%$ SDS, (B) Emission spectra of DAC (12.93-161.60 $\mathrm{ng} / \mathrm{mL})$ in aqueous SDS after excitation at $300 \mathrm{~nm}$.

\subsubsection{Accuracy and Precision}

To prove the accuracy of the developed spectrofluorimetric method, the results of the assay of DAC in pure form, dosage form and spiked human plasma were compared with those obtained using a previously reported spectrofluorimetric method [16]. Statistical comparison of the results obtained by the proposed method and those obtained by the reported method using mean recoveries, 
Student's t-test and variance ratio F-test revealed no significant difference between the two methods regarding accuracy and precision as shown in Table 2, indicating high accuracy and precision of the proposed method.

Table 2 : Statistical analysis of the results of DAC in pure form in $1 \%$ SDS micellar media , compared with Comparison method.

\begin{tabular}{|c|c|c|c|c|c|c|}
\hline \multirow[t]{2}{*}{ Parameter } & \multicolumn{3}{|c|}{ proposed method } & \multicolumn{3}{|c|}{ Comparison method [16] } \\
\hline & $\begin{array}{c}\mathrm{ng} / \mathrm{mL} \\
\text { taken }\end{array}$ & $\begin{array}{l}\mathrm{ng} / \mathrm{mL} \\
\text { found }\end{array}$ & $\%$ Recovery & $\begin{array}{l}\mathrm{ng} / \mathrm{mL} \\
\text { taken }\end{array}$ & $\begin{array}{l}\mathrm{ng} / \mathrm{mL} \\
\text { found }\end{array}$ & $\%$ Recovery \\
\hline & 12.93 & 12.36 & 95.58 & 10.00 & 10.27 & 102.70 \\
\hline & 25.86 & 25.47 & 98.52 & 12.00 & 12.21 & 101.75 \\
\hline & 77.60 & 79.05 & 101.87 & 15.00 & 14.81 & 98.73 \\
\hline & 96.96 & 96.54 & 99.57 & 18.00 & 17.98 & 99.89 \\
\hline & 129.28 & 131.77 & 101.92 & 20.00 & 19.47 & 97.35 \\
\hline & 161.60 & 159.95 & 98.98 & & & \\
\hline $\operatorname{Mean}(\mathrm{X})$ & \multicolumn{3}{|c|}{99.42} & \multicolumn{3}{|c|}{100.08} \\
\hline$\pm \mathrm{SD}$ & \multicolumn{3}{|c|}{2.37} & \multicolumn{3}{|c|}{2.17} \\
\hline $\begin{array}{c}\text { No of } \\
\text { experiments }\end{array}$ & \multicolumn{3}{|c|}{6} & \multicolumn{3}{|c|}{5} \\
\hline Variance & \multicolumn{3}{|c|}{5.60} & \multicolumn{3}{|c|}{4.74} \\
\hline FF-test & \multicolumn{6}{|c|}{$1.18 \quad(6.25)^{*}$} \\
\hline $\begin{array}{l}\text { Students t- } \\
\text { test }\end{array}$ & \multicolumn{6}{|c|}{$0.47 \quad(2.26)^{*}$} \\
\hline
\end{tabular}


*N.B. Figures between parentheses are the tabulated $F$ and $t$ values respectively at $P=0.05[29]$.

\subsubsection{Repeatability}

The repeatability (intraday precision) was evaluated through replicate analysis of the studied drug in pure form and in spiked human plasma using three different concentrations $(25.00,77.60$ and $129.28 \mathrm{ng} / \mathrm{mL})$ and in a Daklanork tablet ${ }^{\circledR}$ using three different concentrations $(30.00,60.00$ and $75.00 \mathrm{ng} / \mathrm{mL})$. Each concentration was measured three successive times and the results are summarized in Table 3.

\subsubsection{Intermediate Precision}

The Intermediate Precision (inter-day precision) was evaluated through replicate analysis of the studied drug in pure form and in tablet on three successive days. The results are juxtaposed in Table 3. The precision of the proposed method was fairly high, as indicated by the low values of SD and \%RSD, respectively. Also, the inter-day and intra-day accuracy was proved by the low values of $\% \mathrm{E}$.

\subsubsection{Specificity}

The specificity of the proposed spectrofluorimetric method was proven by its ability to determine DAC in both a pharmaceutical preparation and plasma without interference from excipients or preservatives that commonly present in the matrix and plasma content. 


\subsubsection{Stability of reference and working solutions}

Solutions of the drug were stable for two weeks when kept in the refrigerator. No change in the FI appeared throughout the whole validation procedures.

\subsubsection{Robustness of the method}

The robustness of the proposed method was demonstrated by the constancy of the FI with minor changes in the experimental conditions, such as SDS volume $2.00 \pm 0.05 \mathrm{~mL}$. These minor changes that may take place during the experimental operation did not affect the FI.

\subsection{Application}

\subsubsection{Determination of DAC in pharmaceutical dosage form}

The proposed method after sample pre-treatment as discussed before under section 2.4.2. was successfully used to quantify DAC in pharmaceutical dosage form (Daklanork $®$ tab) as shown in Table 3. A standard addition technique was used to assess the matrix effect of the tablet additives and its contribution in the deviation of the results obtained by the proposed method as shown in Table 4 . The obtained results revealed no significant matrix effect.

\subsubsection{Determination of DAC in spiked human plasma}

The proposed method after sample pretreatment as discussed before under section 2.4.3. was successfully used to determine DAC in spiked human plasma as shown in Table 5. Standard addition technique was used to assess the matrix effect of the plasma and its contribution in the deviation of the results obtained by the 
proposed methods, the obtained results revealed no significant matrix effect (see Table 5). Table 3A. Repeatability and reproducibility precision data of the proposed spectrofluorimetric method for the determination of DAC in pure, dosage form (Daklanork ${ }^{\circledR}$ tablet (60 mg DAC/tab) and spiked human plasma.

\begin{tabular}{|l|l|l|l|}
\hline Precision & Conc. $(\mathrm{ng} / \mathrm{mL})$ & Pure form & plasma \\
\hline $\begin{array}{l}\text { Intra-day } \\
\text { precision }\end{array}$ & 25.00 & $98.30 \pm 1.68$ & $93.46 \pm 1.85$ \\
\cline { 2 - 4 } & 77.60 & $101.37 \pm 1.10$ & $98.62 \pm 1.97$ \\
\cline { 2 - 4 } & 129.28 & $100.15 \pm 0.82$ & $96.04 \pm 0.96$ \\
\hline $\begin{array}{l}\text { Inter-day } \\
\text { precision }\end{array}$ & 25.00 & $98.78 \pm 2.01$ & $94.52 \pm 1.71$ \\
\cline { 2 - 4 } & 77.60 & $101.76 \pm 1.14$ & $97.12 \pm 1.55$ \\
\cline { 2 - 4 } & 129.28 & $100.45 \pm 0.56$ & $95.25 \pm 1.25$ \\
\hline
\end{tabular}

Table 3B. Repeatability and reproducibility precision data of the proposed spectrofluorimetric method for the determination of DAC in dosage form (Daklanork® tablet (60 mg DAC/tab).

\begin{tabular}{|l|l|l|}
\hline Precision & Conc. $(\mathrm{ng} / \mathrm{mL})$ & Dosage form \\
\hline \multirow{2}{*}{$\begin{array}{l}\text { Intra-day } \\
\text { precision }\end{array}$} & 30.00 & $103.28 \pm 1.01$ \\
\cline { 2 - 3 } & 60.00 & $101.90 \pm 1.47$ \\
\cline { 2 - 3 } & 75.00 & $102.17 \pm 1.02$ \\
\hline $\begin{array}{l}\text { Inter-day } \\
\text { precision }\end{array}$ & 30.00 & $103.84 \pm 1.01$ \\
\cline { 2 - 3 } & 60.00 & $100.85 \pm 1.52$ \\
\cline { 2 - 3 } & 75.00 & $101.64 \pm 1.44$ \\
\hline
\end{tabular}

* Each result is the average of three different separate determinations. 
Table 4. Results obtained by applying the proposed method for the determination of DAC in Daklanork ${ }^{\circledR}$ tab (60 mg DAC/tab) dosage form and results obtained by applying standard addition technique.

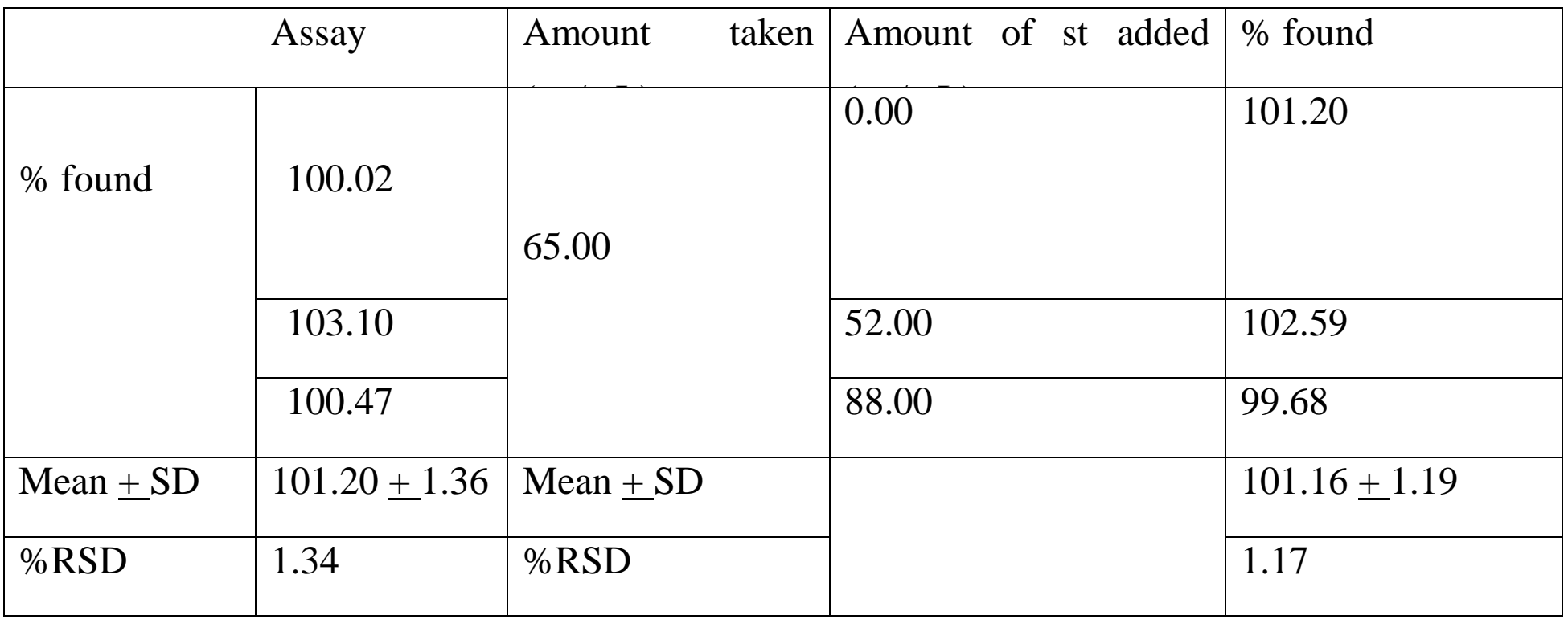

*Each result is the average of three different separate determinations

Table 5. Results obtained by applying the proposed method for the determination of DAC in spiked plasma and results obtained by applying standard addition technique.

\begin{tabular}{|l|l|l|l|l|}
\hline \multicolumn{2}{|c|}{ Assay } & $\begin{array}{l}\text { Amount taken } \\
(\mathrm{ng} / \mathrm{mL})\end{array}$ & $\begin{array}{l}\text { Amount of standard } \\
\text { added }(\mathrm{ng} / \mathrm{mL})\end{array}$ & \% found \\
\hline \multirow{3}{*}{$\%$ found } & 93.30 & & & 95.42 \\
& & \multirow{3}{*}{55.12} & 0.00 & \\
\cline { 2 - 4 } & 94.76 & & 36.00 & 94.20 \\
\cline { 2 - 3 } & 98.20 & & 66.00 & 96.94 \\
\hline Mean \pm SD & $95.42 \pm 2.52$ & Mean \pm SD & & 1.44 \\
\hline \%RD & 2.64 & \%RSD & & $95.52 \pm 1.37$ \\
\hline
\end{tabular}

*Each result is the average of three different separate determinations. 
3.4. Mechanism of the micellar enhancement effect of SDS on DAC $\mathrm{HCl}$ fluorescence

To establish whether the sensitization process of DAC fluorescence was only due to an increase in quantum yield, or whether it was affected by an increase in absorption at the excitation wavelength, the molar absorptivity $(\varepsilon)$ of DAC in the presence of SDS was determined at $300 \mathrm{~nm}$ excitation. Table 6 shows that the $\varepsilon$ micelle: $\varepsilon$ water ratio was approximately 1.0 , which indicates that the increase in sensitivity is not affected by an increase in the light absorption of the studied drug but is due to an increase in the quantum yield of DAC. A likely contributing factor here is the protection of the lowest excited singlet state in the micellar micro-environment from non-radiative processes [18]. In addition, sequestering of the drug into SDS can potentially cause a decrease in non-radiative energy loss via molecular collisions resulting in an enhancement of the fluorescence quantum efficiency [27]. The optimum concentration of SDS is $6.90 \mathrm{mM}$ which is above the critical micelle concentration value $(6 \mathrm{mM})$ showing that the presence of micelles significantly enhances the DAC fluorescence intensity [25]. Also, the DAC absorption spectrum at $300 \mathrm{~nm}$ increased when SDS was added (Table 6), which is consistent with the fluorescence enhancement. In future work, computational modelling might also reveal better understanding of the importance of DAC interactions with polar and non-polar regions of the micelle and the effect this has on the density of excited states.

The forced degradation studies also give information about the chemical behaviour of the drug molecule as they are carried out to determine the intrinsic stability of a drug substance in formulation. To the best of our knowledge, this study is the first reported stability-indicating spectrofluorimetric method for the determination of DAC in tablets and spiked human plasma. 


\subsection{Results of stability indicating assay}

DAC was found to be highly labile to alkaline hydrolysis after exposing it in its tablet form to alkaline degradation in $0.1 \mathrm{~N} \mathrm{NaOH}$, where $28.76 \%$ of the drug was degraded after $2 \mathrm{hrs}$ and $52.12 \%$ degradation occurs after $24 \mathrm{hrs}$. DAC in its dosage form was also exposed to acidic degradation using $0.1 \mathrm{~N} \mathrm{HCl}$ for $24 \mathrm{hrs}$ resulted in about $25.35 \%$ degradation.

Exposure of DAC in its Daklanork tablet form to oxidative degradation by $30 \%$ $\mathrm{H}_{2} \mathrm{O}_{2}$ for $24 \mathrm{hrs}$ resulted in about 55\% degradation of DAC. Tablets were also subjected to $70^{\circ} \mathrm{C}$ for $3 \mathrm{hrs}$ in a water bath. Mild degradation (20\%) was observed which indicates that DAC in its tablet form is thermally stable. Exposing DAC in capsules to sunlight also revealed that it is strongly affected by sunlight after exposure for $24 \mathrm{hrs}$.

Table 6: Determination of the molar absorptivity of $\mathrm{DAC} \mathrm{HCl}$ in aqueous and micellar media:

\begin{tabular}{|l|l|l|l|l|l|}
\hline $\begin{array}{l}\text { Concentration } \\
\text { taken }(\mu \mathrm{g} / \mathrm{mL})\end{array}$ & $\begin{array}{l}\text { Absorbance In } \\
\text { aqueous } \\
\text { medium at } \\
300 \mathrm{~nm}\end{array}$ & $\varepsilon$ water & $\begin{array}{l}\text { Absorbance In } \\
\text { micellar } \\
\text { medium at } \\
300 \mathrm{~nm}\end{array}$ & $\begin{array}{l}\varepsilon \\
\text { micellar }\end{array}$ & at \\
\hline 16 & 0.628 & 31863 & 0.76 & 35618 & 1.12 \\
\hline 8 & 0.351 & 35618 & 0.419 & 42518 & 1.19 \\
\hline 4.5 & 0.177 & 31931 & 0.213 & 38426 & 1.20 \\
\hline 13 & 0.5053 & 31554 & 0.573 & 35782 & 1.13 \\
\hline
\end{tabular}




\section{Conclusion}

In this article, we have developed and optimized a new spectrofluorimetric assay for DAC combined with a micellar enhancement of the fluorescence signal. The fact that our methodology is optimal in water rather than common organic solvents such as methanol leads to a greener chemistry approach as well as being simple, precise, accurate, economical and robust. Furthermore, it can be applied for the determination of DAC in bulk drug, tablet content and in spiked human plasma. The results shown in this work indicate the validity of our approach for application in routine quality control analysis since it is characterized by clinically-relevant sensitivity, selectivity and simplicity. 


\section{References.}

1. Frank, C., et al., The role of parenteral antischistosomal therapy in the spread of hepatitis $C$ virus in Egypt. The Lancet, 2000. 355(9207): p. 887-891.

2. Sagnelli, C., et al., Liver fibrosis in human immunodeficiency virus/hepatitis $C$ virus coinfection: Diagnostic methods and clinical impact. World J Hepatol, 2015. 7(24): p. 251021.

3. Alter, M.J., Epidemiology of hepatitis C virus infection. World Journal of Gastroenterology, 2007. 13(17): p. 2436-2441.

4. Kumar, S. and I. M. Jacobson, Antiviral therapy with nucleotide polymerase inhibitors for chronic hepatitis C. Vol. 61. 2014.

5. Rezk, M.R., et al., Development and validation of sensitive and rapid UPLC-MS/MS method for quantitative determination of daclatasvir in human plasma: Application to a bioequivalence study. Journal of pharmaceutical and biomedical analysis, 2016. 128: p. 6166.

6. Bodavari, S., The merck index. 2006: Monograph.

7. Organization, W.H., Patent situation of key products for treatment of hepatitis C. 2014. 2016.

8. Pol, S., M. Corouge, and A. Vallet-Pichard, Daclatasvir-sofosbuvir combination therapy with or without ribavirin for hepatitis $C$ virus infection: from the clinical trials to real life. Hepat Med, 2016. 8: p. 21-6.

9. Ragab, G.H.A., Stability indicating hplc method development and validation for determination of daclatasvir in pure and tablets dosage forms. INDO american Journal of Pharmaceutical scienes, 2017. 3.

10. Eldin, A.S., et al., The Development of A New Validated HPLC and Spectrophotometric Methods for the Simultaneous Determination of Daclatasvir and Sofosbuvir: Antiviral Drugs. Journal of Pharmacy and Pharmacology Research, 2017. 1(1): p. 28-42.

11. MagdyAtef Wadie1, S.M.M., Sobhy Mohamed El.Adl3, Mohamed Saleh Elgawish, Development andValidation of a New, Simple-HPLC Method for Simultaneous Determination ofSofosbuvir, Daclatasvir and Ribavirin in Tablet Dosage Form. Journal of Pharmacy and Biological Sciences, 2017. 12(5): p. 60-68.

12. Jiang, H., et al., Multiplexed LC-MS/MS method for the simultaneous quantitation of three novel hepatitis $C$ antivirals, daclatasvir, asunaprevir, and beclabuvir in human plasma. Journal of pharmaceutical and biomedical analysis, 2015. 107: p. 409-418.

13. Azab, S.M. and A.M. Fekry, Electrochemical design of a new nanosensor based on cobalt nanoparticles, chitosan and MWCNT for the determination of daclatasvir: a hepatitis $C$ antiviral drug. RSC Advances, 2017. 7(2): p. 1118-1126.

14. Kumar, A.P., Method development and validation of ultraviolet-visible spectroscopic method for the estimation of hepatitis-C drugs - daclatasvir and sofosbuvir in active pharmaceutical ingredient form. Vol. 9. 2016. 61-66.

15. Kekan, V., S. Gholve, and O. Bhusnure, Development, Validation and Stability Study of UV Spectrophotometric Method for Determination of Daclatasvirin Bulk and Pharmaceutical Dosage Forms. Int J ChemTech Res, 2017. 10: p. 281-287. 
16. Abo-Zeid, M.N., et al., Ultrasensitive spectrofluorimetric method for rapid determination of daclatasvir and ledipasvir in human plasma and pharmaceutical formulations. Journal of pharmaceutical and biomedical analysis, 2018. 152: p. 155-164.

17. Yang, H.-M., et al., Synchronous fluorescence determination of urinary 1-hydroxypyrene, 6 naphthol and 9-hydroxyphenanthrene based on the sensitizing effect of b-cyclodextrin. Analytica chimica acta, 2009. 636(1): p. 51-57.

18. Elshahed, M.E. and I. Habib, Stability-Indicating Micelle-Enhanced Spectrofluorimetric Method For Determination of Tamsulosin Hydrochloride In Dosage Forms. JOURNAL OF ADVANCES IN CHEMISTRY, 2015. 11(2): p. 3513-3531.

19. Walash, M., et al., Stability-indicating micelle-enhanced spectrofluorimetric method for determination of loratadine and desloratadine in dosage forms. Luminescence, 2011. 26(6): p. 670-679.

20. Walash, M., et al., Micelle-enhanced spectrofluorimetric determination of amlexanox in bioadhesive buccal tablets: application to content uniformity testing. Luminescence, 2015. 30(6): p. 823-829.

21. Turro, N.J. and A. Yekta, Luminescent probes for detergent solutions. A simple procedure for determination of the mean aggregation number of micelles. Journal of the American Chemical Society, 1978. 100(18): p. 5951-5952.

22. Saha, P., et al., Effect of an anionic surfactant (SDS) on the photoluminescence of graphene oxide (GO) in acidic and alkaline medium. RSC Advances, 2018. 8(1): p. 584-595.

23. Mcelroy, C.R., et al., Tools and techniques for solvent selection: green solvent selection guides. Sustain Chem Process, 2016. 4(1).

24. Breslow, R., The principles of and reasons for using water as a solvent for green chemistry. Handbook of Green Chemistry: Online, 2010: p. 1-29.

25. Kaur, K., B. Singh, and A.K. Malik, Micelle enhanced spectrofluorimetric method for the determination of ofloxacin and lomefloxacin in human urine and serum. Thai Journal of Pharmaceutical Sciences, 2010. 34(2).

26. Vílchez, J.L., et al., Micelle-enhanced spectrofluorimetric method for the determination of antibacterial trovafloxacin in human urine and serum. Microchimica Acta, 2005. 150(3-4): p. 247-252.

27. Yu, F., et al., Sensitive determination of prulifloxacin by its fluorescence enhancement on terbium (III)-sodium dodecylbenzene sulfonate system. Analytical letters, 2008. 41(17): p. 3124-3137.

28. Guideline, I.H.T. Validation of analytical procedures: text and methodology Q2 (R1). in International Conference on Harmonization, Geneva, Switzerland. 2005.

29. Miller, J. and J.C. Miller, Statistics and chemometrics for analytical chemistry. 2018: Pearson education. 